\title{
RSM approach for modeling and optimization of designing parameters for inclined fins of solar air heater
}

\begin{abstract}
In the present study, a simulation and response surface methodology (RSM) combined approach has been applied to investigate the thermal and thermo-hydraulic performance parameter (THPP) of solar air heater (SAH) with inclined fins. CFD based software (ANSYS Fluent v16.1) is used to simulate the SAH. RNG k- $\mathcal{E}$ turbulence model was selected to carry out a two-dimensional simulation modeling. Moreover, RSM is applied to analyze the results of finite volume method and to optimize the process parameters of SAH. A numerical model describing the heat transfer characteristics of SAH having inclined fins has been developed and employed to study the effects of various design of fins on the average Nusselt number, fiction factor as well as THPP. The study covered different length of fin in the range of 1.5$2.5 \mathrm{~mm}$, different slant angle $(\alpha)$ of fin in the range of $30^{\circ}-60^{\circ}$, different pitch $(\mathrm{P})$ of fin in the range of 15-25 mm, and a range of 4000-24,000 for the Reynolds numbers. Based on results of the model, the optimized values of design parameters for the optimal operation of SAH to provide the optimal THPP of 1.928 were found to be; length of fin $=1.52 \mathrm{~mm}$, the pitch of fin $=19.04 \mathrm{~mm}$, slant angle $=49^{\circ}$ and Reynolds number at 18243.5. According to the optimized values of design parameters, the enhancement ratio of Nusselt number and friction factor were found to be 2.53 and 2.22 , respectively. Finally, the thermal performance of the proposed inclined fin in terms of THPP was compared to other roughness geometries, such as circle $\quad($ THPP $=1.65)$, square-sectioned $($ THPP $=1.80)$ and L-shaped $($ THPP = 1.90). Accordingly, a better THPP of 1.928 was observed for the current study.
\end{abstract}

Keyword: Solar air heater; Inclined fins; CFD; RSM 